\title{
THE ROLE OF IMPULSIVITY IN PREDICTING THE SUBJECTIVE WELL-BEING OF STUDENTS IN PRIVATE HIGHER EDUCATION
}

\author{
Katarina Sokićii, \\ Fayyaz Hussain Qureshi², \\ Sarwar Khawaja ${ }^{3}$ \\ ${ }^{1}$ Dr., Research Associate, \\ Oxford Business College, \\ 65 George Street, Oxford, \\ United Kingdom \\ orcid.org/0000-0001-7522-1228 \\ ${ }^{2}$ Dr., Director of Research and Quality Assurance, \\ Oxford Business College, \\ 65 George Street, Oxford, \\ United Kingdom \\ ${ }^{3}$ Chairman Business Development, \\ Oxford Business College, \\ 65 George Street, Oxford, \\ United Kingdom
}

\begin{abstract}
:
The primary purpose of this study was to investigate associations between attention impulsivity, motor impulsivity and non-planning impulsivity measured according to the Barratt Impulsiveness Scale-11 (BIS) and indicators of subjective well-being (SWB) measured by the Flourishing Scale (FS) and Personal Wellbeing Index (PWI) in students at selected private higher education institutions ( $\mathrm{N}=514,52 \%$ women, $48 \%$ men). The aim of the current study was to explore the impact of gender on the aforementioned associations. Relationships between impulsivity and subjective well-being were examined taking into account the multifactoral structure of impulsiveness. The main findings of the study show that: (a) attention impulsivity predicted low prosperity and low levels of satisfaction with standard of living, health, personal achievements, safety and future security; (b) motor impulsivity showed bivariate but not unique relationships between prosperity and satisfaction with personal health, achievements and personal safety; (c) non-planning impulsivity was found to be uniquely associated with lower subjective prosperity and lower satisfaction with personal achievements and personal relationships; and (d) gender did not moderate the relationship between BIS components and SWB indexes. Impulsivity substrates explained between 4 and $17 \%$ of the variance in
\end{abstract}

i Correspondence: email katarina.sokić@oxfordbusinesscollege.ac.uk 
subjective well-being indexes. In sum, the results showed that the three components of impulsivity are distinct yet partially overlapping.

Keywords: attention impulsivity, motor impulsivity, non-planning impulsivity, subjective well-being, private higher education

\section{Introduction}

Impulse control, good behavioural regulation, and emotional stability are some of the key prerequisites for personal well-being, life satisfaction, and overall health. Furthermore, these personal qualities and abilities are a prerequisite for success in private and business life. Poor impulse control is related to high impulsivity and often leads to violations and consequently problems with the community and the law. Impulsivity is a relatively stable personality trait characterized by a constellation of cognitive, behavioural and emotional features including a low inhibitory control, irresponsibility, impatience, a lack of planfulness and foresight, alienation and distrust, often linked to socially deviant behaviours (e.g., Moeller et al., 2001; Stanford et al., 2009). Impulsivity is considered to be a complex psychological construct involving attention deficits, motor restlessness, and lack of planning (Patton et al., 1995).

Impulse control problems are reflected in many areas of life, including quality of life, academic achievement, the standard of living. Previous studies (Lozano \& Pérez, 2014; Vigil-Colet \& Morales-Vives, 2005) showed that impulsivity was negatively related to intelligence and academic performance (especially among bright students). However, both of these studies have shown that impulsivity is a moderator between individuals' resources and their achievements.

In terms of personality, disinhibition can be viewed as a link between impulsivity and negative affectivity is disinhibition (e.g., Krueger, 1999a; Sher and Trull, 1994). Prominent behavioural manifestations of disinhibition are irresponsibility, impatience, impulsive action leading to negative outcomes, alienation from others and distrust of others, aggression (especially reactive) (Patrick \& Drislane, 2015; Patrick et al., 2009).

There is a broad consensus that impulsivity plays an important role in some forms of aggressive behaviour and in self-harm (e.g., Coccaro et al., 2010; Coccaro et al., 2005; Eronenet al., 1996; Paris, 2005). Many authors emphasized that impulsivity is a major component of undesirable and socially unacceptable behaviour in the constellation of personality traits (e.g., Krueger et al., 2007; Patrick \& Bernat, 2009). Numerous studies showed that impulsivity is related to maladaptive traits associated with externalized problems (e.g., antisociality, aggressive behaviour toward others, impulsive buying, disinhibition, uncontrolled gambling, hypersexuality (Smith et al., 2006; Sokić et al., 2021; Sokić, 2017).

Impulsivity is a significant predictor of different types of risky behaviours (Bakhshani, 2014), and impulsive acts usually occur in response to the failure of individuals to resist calls or temptations arising from internal or external stimuli 
(American Psychiatric Association, 2013). Externalisation includes a wide range of pathological behaviours including childhood behavioural problems, adult crime, and aggression, and various forms of addiction (Krueger et al., 2007; Young et al., 2000). Research shows that different forms of externalization are associated with antisocial deviations. For example, the impulsive Antisocial Factor contained in PPI-R shows a strong association with externalized psychopathy factor (Blonigen et al., 2005). On the other hand, impulsivity is associated with internalised difficulties such as anxiety, suicidality, depression, self-harming, substance abuse (Swann et al., 2005; Swann et al., 2008; Lane et al., 2007). In the student population, impulsivity is associated with grandiose and vulnerable narcissism, negative affect, difficulties with completing activities, irritability, anxiety, difficulty concentrating, reactive and proactive agression (Hecht \& Latzman, 2015; Malesza \& Kaczmarek, 2018; Sperry, 2016). As we can see from the above studies, impulsivity is mostly associated with negative outcomes. This paper examined the role of impulsivity in positive outcomes such as flourishing and personal well-being that include satisfaction with different aspects of life. These relationships have not been sufficiently examined, especially given that impulsivity is a complex multidimensional psychological construct and that the dimensions of impulsivity have different separate relationships with external positive outcomes.

\subsection{Impulsivity as a multifactorial psychological construct}

Some of the most dominant models of impulsivity are the Barratt model of impulsivity (Barratt, 1993) and the UPPS-P model (Cyders et al., 2007; Whiteside \& Lynam, 2001). Both of them has been developed based on a multifactorial understanding of impulsivity. According to the Barratt's model, three second-order factors reflect impulsivity's three theoretical dimensions: attentional impulsivity, motor impulsivity, and non-planning impulsivity (Patton et al., 1995). Attentional impulsivity refers an inability to focus attention, motor impulsivity involves acting without thinking, and non-planning impulsivity reflects a lack of future orientation or forethought.

In order to explore the structure of impulsivity that includes different theoretical approaches and models, Whiteside and Lynam (2001) factorized several scales of impulsivity and obtained four factor structure of impulsivity which includes urgency (tendency to commit rash or regrettable actions as a result of negative affect), lack of premeditation (tendency to act without thinking or planning), lack of perseverance (inability to remain focused on a task and boredom intolerance), and sensation seeking (tendency to seek excitement and adventure, see Whiteside \& Lynam, 2001). Subsequently, Cyders et al. (2007) renamed urgency scale into negative urgency and add positive urgency subscale which refers to impulsive behavior arising from positive affect.

All three BIS subscales were negatively correlated with conscientiousness, motor impulsivity was positively related to extraversion, whereas attentional impulsivity was positively related to neuroticism (Lange et al., 2017). Malesza \& Ostaszewski (2016) found that the Dark Triad subscales of narcissism, which is positively associated with happiness (Paulhus \& Williams, 2002) positively correlated with all subscales of the BIS-11. In 
contrast, psychopathy positively correlated with attention and motor impulsivity. Additionally, boldness as a marker of psychological well-being and correlate of adaptive functioning in triarchic model of psychopathy (Patrick \& Drislane, 2015) was predicted low attentional and low non-planning impulsivity (Gatner et al., 2016).

The role of different impulsivity dimensions in multidimensional frameworks of personality is not well explored. Research has shown that all three BIS subscales are negatively correlated with conscientiousness, motor impulsivity is positively related to extraversion, whereas attentional impulsivity is positively related to neuroticism (Lange et al., 2017). The results of derivation the UPPS from the Five-Factor Model of Personality have shown that negative urgency is associated with the impulsiveness facet of neuroticism, lack of premeditation with the low deliberation facet of conscientiousness, lack of perseverance with the low self-discipline facet of conscientiousness, and sensation seeking with the excitement seeking facet of extraversion (Whiteside \& Lynam, 2001). Previous research on non-forensic (i.e., student and community) populations suggested that impulsivity may be conceived of as extreme variants of normal personality traits. Studies showed that people with a high level of impulsivity have problems in interpersonal relationships, problems in establishing stable partnerships. Further, the impulsivity often leads to deprresive episodes, interruptions in education, changing jobs, and risky decisions often associated with seeking instant gratification regardless of future consequences (Lozano et al., 2014; Rodriguez-Jimenez et al., 2006; Swann et al., 2008; Stanford et al., 2009).

\subsection{Impulsivity and subjective well-being - Literature review}

Subjective well-being (SWB) is a common term for diverse concepts ranging from momentary moods to happiness and life satisfaction (Diener, 1999; Diener et al., 2003; Diener et al., 2002). SWB represents a cognitive process in which the individual perception of one's general aspects of life is used as an evaluation criterion (Pavot \& Diener, 2008). The components of SWB are organised hierarchically: at the highest level, SWB reflects a general evaluation of a person's life; at the next highest level, SWB is composed of positive affect, negative affect, satisfaction and domain satisfaction (Dieneret al., 2003).

At first glance, impulsivity could be negatively related to life satisfaction. Namely, impulsivity is associated with an unhealthy lifestyle such as addictive, risky and hedonistic behaviours (Goodwin et al., 2017; Loxton \& Dawe, 2001). This lifestyle predicts low subjective well-being. Furthermore, impulsivity is positively associated with negative correlates of happiness, such as mood disorders (Swann et al., 2008), suicide attempts (Dougherty et al., 2004), depression (Van Den Eynde et al., 2008) and anxiety (Xiaet al., 2017). Furthermore, Impulsivity is related to socially unacceptable behaviours like aggression (Houston et al., 2003), and destructive communication (Tan et al., 2017). Therefore, in the long run, impulsive individuals have impaired social and intimate relationships. Successful close relationships are an essential component of life satisfaction and happiness (Demir, 2010). Previous research has shown that impulsivity is associated 
with unhealthy (pathological) love (Sophia et al., 2009) and low one's own and partner's marital satisfaction (Tan et al., 2017). Additionally, impulsivity traits correlated negatively with self-regulation positively related to subjective well-being and positive affect (Hofmann et al., 2014).

SWB is considered to be a hallmark of mental health (Fredrickson, 1998). Impulsivity per se is a diagnostic criterion for a wide range of mental disorders including attention-deficit/hyperactivity disorder (ADHD), borderline personality disorder, bulimia, antisocial personality disorder (APA 2013) and therefore is expected to be related to poorer SWB.

The relationship between impulsivity and SWB is intriguing but has not been sufficiently explored, so it is still unclear what role impulsivity plays in an individual's subjective well-being. Previous research has found that rash impulsivity measured by a short version of the Barratt Impulsivity Scale (BIS-11; Spinella, 2007) was negatively associated with SWB (Goodwin et al., 2017). However, to the best of our knowledge, the relationship between certain impulsivity dimensions and personal well-being indicators has not been examined so far.Given these gaps, the impact of impulsivity as a multidimensional construction on flourishing and different aspects of life satisfaction will be examined in a sample of students in private higher education. The private higher education sector is growing globally (Qureshi \& Khawaja, 2021). Moreover, it, therefore,deserves special attention due to its specifics. This student population is growing and therefore deserves special attention due to its specifics. Namely, these are often international students who pay for their education, which entails studying full time and part time work. In such circumstances, which are also affected by the COVID 19 pandemic (Qureshi et al., 2020), work-life balance is important factor for both academic and personal success and subjective well-being.

\subsection{The current study and hypotheses}

The current study aimed to examine the relationship between the different dimensions of impulsivity (i.e. attentional impulsivity, motor impulsivity, and non-planning impulsivity) as indexed by the BIS-11 and indicators of SWB (flourishing and personal wellbeing index) in the student population in private higher education. A secondary aim was to investigate the relation between impulsivity and SWB according to gender.

Previous study shown that attentional impulsivity is related to measures of maladaptive functioning such as neuroticism (Lange et al., 2017), manic and depressive episodes (Swann et al., 2008), and suicide attempts (Dougherty et al., 2004). In line with these findings, we predicted that attentional impulsivity would be associated with low SWB (Hypothesis 1). Based on empirical evidence showing that motor impulsivity is related to low conscientiousness (Malesza \& Ostaszewski, 2016), low impulsive control, low planning, and organisation (Spinella, 2005), we predicted that motor impulsivity would be related to low SWB (Hypothesis 2). Since non-planning impulsivity includes lack of premeditation (e.g., acting at the moment without regard to consequences) and is associated with substance abuse (Skinner et al., 2004; Dom et al., 2006), and depressive 
episodes (Swann et al., 2008) we hypothesized that non-planning impulsivity would be associated with low SWB (Hypothesis 3).

Previous research showed no significant gender differences on each of the BIS subscales (e.g., Malesza \& Ostaszewski, 2016) as well BIS-11 total scores (e.g., Patton et al., 1995), as such, we expected to find similar results in the current study. Correlations between BIS-11 subscales and the SWB indexes were examined separately in men and women to determine whether correlations for BIS subscales with criterion measures differ depending on gender.

\section{Materials and method}

\subsection{Participants and procedure}

The sample consisted of 557 students from various private universities and colleges in Croatia Unfortunately, the questionnaires of 43 participants were excluded from analyses due to missing data, and thus the final sample comprised 514 students (52\% woman, $48 \%$ men), ranging in age from 19 to $36(M=22$ and $S D=1.78)$. Table 1 shows the frequencies of students from different study programs who participated in the study. The survey was conducted in the period from May 2020 to January 2021. The study protocol was approved by the Ethics Committee from the Department of Psychology, Faculty of Humanities and Social Sciences, University of Zagreb.

Participation was on a voluntary basis and students gave their written consent before completing the study. They were asked to complete a battery of self-report measures anonymously and received no course credit compensation for their participation. Participants were informed that they could withdraw from the research at any time and that the results will be presented only for groups.

Table 1: Frequencies of students from different study proggrame

\begin{tabular}{|l|c|c|}
\hline & $\mathbf{F}$ & $\mathbf{\%}$ \\
\hline Finance & 153 & 30,0 \\
\hline Digital marketing & 37 & 7,2 \\
\hline Computing & 178 & 34,6 \\
\hline System engineering & 25 & 4,9 \\
\hline Design and communications management & 41 & 8,0 \\
\hline Software engineering & 52 & 10,1 \\
\hline Visual communications design & 28 & 5,2 \\
\hline Total & 514 & $100,0 \%$ \\
\hline
\end{tabular}

\subsection{Measures}

\subsubsection{Barratt Impulsiveness Scale-11 (BIS-11)}

The Barratt Impulsiveness Scale-11 (BIS-11; Patton et al., 1995) is a 30-item self-report measure of impulsivity's personality/behavioural construct.. It consists of six first order factors: attention (5 items), motor (7 items), self-control (6 items), cognitive complexity (5 items), perseverance (4 items) and cognitive instability (3 items). Three BIS-11 second- 
order factors are attention impulsivity (attention and cognitive instability) (e.g., I don't „pay attention"), motor impulsivity (motor and perseverance) (e.g., I do things without thinking), and non-planning impulsivity (self-control and cognitive complexity) (e.g., I am more interested in the present than the future). A total score is obtained by summing the second-order factors. The items are answered using a 5-point Likert scale ranging from rarely/never to almost always Cronbach's $\alpha$ coefficients in the current study were .78, .60, .62 , and .63 for the BIS sum score and the three subscales (attention, motor and nonplanning), respectively.

\subsubsection{Flourishing scale (FS)}

Subjective well-being was measured by the Flourishing Scale (FS; Diener et al., 2010). The FS consists of eight items (e.g., My social relationships are supportive and rewarding, I am engaged and interested in my daily activities, I am competent and capable in the activities that are important to me) to measure a person's overall well-being conceptualised as socialpsychological prosperity in important aspects of functioning, such as relationships, selfesteem, purpose, and optimism. A total of eight items were answered using a 7-point scale, ranging from 1 (strongly disagree) to 7 (strongly agree). A high score indicates good psychological resources and strength. In the current study, the scale has been reported to have high levels of internal consistency (Cronbach's $\alpha=.86$ ).

\subsubsection{Personal Wellbeing Index - (PWI)}

Personal well-being was measured using the PWI (International Wellbeing Group, 2013). The PWI consists of seven items, for which participants are asked to indicate their level of satisfaction with each of seven variety of life domains. Each domain makes a unique contribution to the explained variance of PWI. The PWI domains assessed include the standard of living, health, achieving in life, relationships, safety, community connectedness, and future security. Items are scored using a 10-point Likert-type scale ranging from 1 (very very unsatisfied) to 10 (very dissatisfied). A total of eight items were answered using a 7-point scale, ranging from 1 (strongly disagree) to 7 (strongly agree). Internal consistency of the PWI was good in the present study (Cronbach's $=0.84$ ).

\subsection{Statistical analysis}

The relationship between three dimensions of impulsivity and SWB indicators was investigated through zero-order correlations. The contribution of impulsivity in the prediction of SWB was explored through hierarchical multiple regression analysis in which scores for the three BIS subscales were entered as predictors of criterion variables consisting of the Flourishing scale and Personal Wellbeing Index. In all regression models, gender and age was entered at Step 1, and BIS subscales at Step 2. To explore the impact of gender on the predicted associations, a series of hierarchical linear regression models were computed using each criterion measure as the dependent variable. The scores on the BIS-11 subscales and gender were entered as predictors at Step 1, and Gender x BIS-11 subscales interaction entered separately in Step 2. 


\section{Results}

\subsection{Descriptive statistics}

Descriptive statistics for all variables are reported in Table 2. As we can see above, all scales demonstrated adequate internal consistency except for the impulsivity subscale. The BIS subscales had some lower internal consistency than optimal which is similar to previous studies (e.g. Gatner et al., 2016; Lange et al., 2017). However, reliabilities of the BIS-11 subscales in some other studies were optimal (e.g., Malesza \& Ostaszewski, 2016). Thus, it seems that the reliabilities of the scales vary across the studies, and, therefore, further checks on the psychometric characteristics of this instrument are needed.

In line with previous findings (Patton et al., 1995) the BIS subscales were correlated significantly with one another from .51 to $36(p<.01)$.

Table 2: Descriptive statistics and gender differences for all variables

\begin{tabular}{|l|c|c|c|c|c|}
\hline & \multicolumn{2}{|c|}{ Men $\mathbf{( N \mathbf { 2 4 7 } )}$} & \multicolumn{2}{c|}{ Woman $\mathbf{( N = \mathbf { 2 6 7 } )}$} & F(1,512) \\
\hline & $M$ & $S D$ & $M$ & $S D$ & \\
\hline BIS-11 Total & 62.15 & 8.81 & 62.45 & 9.87 & .12 \\
\hline Attention Impulsivity & 17.63 & 3.32 & 16.98 & 3.62 & 4.48 \\
\hline Motor Impulsivity & 22.41 & 3.85 & 22.42 & 4.42 & .00 \\
\hline Non-Planning Impulsivity & 22.12 & 4.27 & 23.05 & 4.39 & 5.93 \\
\hline Flourishing & 44.21 & 6.78 & 45.50 & 6.83 & 4.62 \\
\hline PWI Total & 56.31 & 8.99 & 57.84 & 8.30 & 4.05 \\
\hline Standard of Living & 8.19 & 1.78 & 8.16 & 1.80 & .03 \\
\hline Personal Health & 8.01 & 2.07 & 8.12 & 1.99 & .42 \\
\hline Achieving in Life & 7.53 & 1.79 & 8.02 & 1.67 & $10.42^{*}$ \\
\hline Personal Relationships & 7.98 & 1.63 & 8.44 & 1.56 & $10.99^{*}$ \\
\hline Personal Safety & 8.40 & 1.65 & 8.51 & 1.52 & .61 \\
\hline Community-Connectedness & 8.44 & 1.66 & 8.70 & 1.37 & 3.73 \\
\hline Future Security & 7.77 & 1.90 & 7.89 & 1.70 & .60 \\
\hline${ }^{*} p<.01$ & \multicolumn{5}{l}{} \\
\hline
\end{tabular}

Concerning gender, two PWI domains (achieving in life and personal relationships) were significantly higher in women (Table 2), while on flourishing, impulsivity subscales, and on other five PWI domains (standard of living, personal health, personal safety, community-connectedness, future security), and on the impulsivity subscales there were no statistically significant gender differences. Besides, there were no significant differences in correlations between BIS subscales and the SWB indexes across gender tested via Fisher $r$-to- $z$ transformation (see Table 3 and Table 4). 
Table 3: Testing differences between correlation coefficients across gender: $z$ values

\begin{tabular}{|l|c|c|c|c|c|c|}
\hline & \multicolumn{2}{|c|}{$\begin{array}{c}\text { Attention } \\
\text { Impulsivity }\end{array}$} & \multicolumn{2}{c|}{$\begin{array}{c}\text { Motor } \\
\text { Impulsivity }\end{array}$} & \multicolumn{2}{c|}{$\begin{array}{c}\text { Non-Planning } \\
\text { Impulsivity }\end{array}$} \\
\hline & $z$ & $p$ & $z$ & $p$ & $z$ & $p$ \\
\hline Flourishing & -1.27 & 0.2041 & 0.00 & 1.0000 & -0.78 & 0.4354 \\
\hline PWI Total & -0.36 & 0.7188 & 0.80 & 0.4237 & -0.70 & 0.4839 \\
\hline Standard of Living & -0.12 & 0.9045 & 0.57 & 0.5687 & -0.23 & 0.8181 \\
\hline Personal Health & 0.12 & 0.9045 & 1.27 & 0.2041 & 0.23 & 0.8181 \\
\hline Achieving in Life & -2.08 & 0.0375 & -0.58 & 0.5619 & 0.24 & 0.8103 \\
\hline Personal Relationships & -0.23 & 0.8181 & 0.79 & 0.4295 & -1.04 & 0.2983 \\
\hline Personal Safety & 0.23 & 0.8181 & 0.93 & 0.3524 & -0.46 & 0.6455 \\
\hline Community- Connectedness & -0.11 & 0.9124 & 0.45 & 0.6527 & -1.60 & 0.1096 \\
\hline Future Security & 0.34 & 0.7339 & 0.56 & 0.5755 & -0.80 & 0.4237 \\
\hline
\end{tabular}

Consistent with prediction, all three impulsivity dimensions are negatively related to flourishing in both men and women. However, only attentional and motor impulsivity was negatively associated with both Flourishing and PWI Total. As predicted, attentional impulsivity was negatively related to PWI domains standard of living, personal health, achieving in life, and personal safety in both men and women (Hypotheses 1). Contrary to expectation, attentional impulsivity was not related to satisfaction with personal relationships, personal safety, and future security in both men (Table 4).

Hypothesis 2 was partially confirmed. In line with expectation motor impulsivity was negatively related to flourishing. However contrary to expectation it was unrelated to the PWI Total and most of the PWI domain (standard of living, personal relationships, community-connectedness, and future security). Only in women, motor impulsivity was statistically significantly negatively related to personal health and personal safety, while in men these correlations are statistically insignificant. PWI domain achieving in life was negatively related to motor impulsivity only in men but not in women.

In line with the prediction (Hypotheses 3), non-planning impulsivity was negatively associated with Flourishing, PWI Total, and PWI domain achieving in life in both genders. Contrary to prediction, non-planning impulsivity was not associated with a standard of living and personal health domain in both men and women. Only in men, non-planning impulsivity was negatively related to personal relationships, personal safety, and community-connectedness.

Despite these differences in bivariate correlations, gender did not moderate the relationship between BIS subscales and SWB indexes, and therefore all data are reported using the total sample. 
Table 4: Zero-order Pearson Correlations between the BIS Scales and PWI and Flourishing scale in Men ( $\mathrm{N}=247)$ and Woman $(\mathrm{N}=267)$

\begin{tabular}{|l|c|c|c|c|c|c|}
\hline & \multicolumn{2}{|c|}{$\begin{array}{c}\text { Attention } \\
\text { Impulsivity }\end{array}$} & \multicolumn{2}{c|}{$\begin{array}{c}\text { Motor } \\
\text { Impulsivity }\end{array}$} & \multicolumn{2}{c|}{$\begin{array}{c}\text { Non-Planning } \\
\text { Impulsivity }\end{array}$} \\
\hline & Men & Woman & Men & Woman & Men & Woman \\
\hline Flourishing & $-.38^{* *}$ & $-.28^{* *}$ & $-.17^{*}$ & $-.17^{*}$ & $-.39^{* *}$ & $-.33^{* *}$ \\
\hline PWI Total & $-.26^{* *}$ & $-.23^{* *}$ & -.08 & -.15 & $-.23^{* *}$ & $-.17^{*}$ \\
\hline Standard of Living & $-.19^{*}$ & $-.18^{*}$ & -.04 & -.09 & -.07 & -.05 \\
\hline Personal Health & $-.18^{*}$ & $-.19^{*}$ & -.09 & $-.20^{*}$ & -.11 & -.13 \\
\hline Achieving in Life & $-.36^{* *}$ & $-.19^{*}$ & $-.19^{*}$ & -.14 & $-.25^{* *}$ & $-.27^{* *}$ \\
\hline Personal Relationships & -.14 & -.12 & .01 & -.06 & $-.20^{*}$ & -.11 \\
\hline Personal Safety & $-.18^{*}$ & $-.20^{*}$ & -.12 & $-.20^{*}$ & $-.18^{*}$ & -.14 \\
\hline Community- Connectedness & -.11 & -.10 & .03 & -.01 & $-.18^{*}$ & -.04 \\
\hline Future Security & -.12 & -.15 & .00 & -.05 & -.16 & -.09 \\
\hline${ }^{*} \mathrm{p}<.01,{ }^{* *} \mathrm{p}<.001$ & \multicolumn{7}{|l}{} & & & \\
\hline
\end{tabular}

\subsection{Associations between BIS subscales and SWB indexes}

Table 5 shows relations between the BIS subscales and SWB indexes on the total sample. After controlling for gender and age, results indicated that BIS total scores contributed significantly in explaining all SWB indexes.. In percentage terms, all impulsivity dimensions accounted uniquely for total score variance in SWB indexes as follows: $15 \%$ in flourishing, $9 \%$ in PWI total, $4 \%$ in the standard of living, $4 \%$ in personal health, $14 \%$ in achieving in life, $5 \%$ in personal relationships, $6 \%$ in personal safety, $4 \%$ in communityconnectedness, and $4 \%$ in future security.

As expected, on the total sample attention impulsivity showed expected significant negative associations with flourishing $(r=-.33, p<.001)$, PWI total scores $(r=$ $-.25, p<.001)$, the standard of living $(r=-.18, p<.001)$, personal health $(r=-.19, p<.001)$, achieving in life $(r=-.28, p<.001)$, personal relationships $(r=-.14, p<.01)$, personal safety $(r=-.20, p<.001)$, and future security domains $(r=-.148, p<.01)$. Relationship between attentional impulsivity and personal relationships was reduced to nonsignificance after controlling via regression for variance shared with the other two BIS subscales $(B=-.12$, $\mathrm{p}>.01$ ). Contrary to expectation, bivariate association, as well as regression analyses, showed the nonsignificant relationship between attention impulsiveness and community-connectedness domain $(r=-.11, \AA=-.13, p>.01)$.

Consistent with the prediction, motor impulsivity showed significant but modest negative associations with flourishing $(r=-.17, p<.001)$, and three PWI domains (personal health, achieving in life and personal safety). However, these associations between motor impulsivity and three PWI domains was reduced to nonsignificance when all BIS subscales were examined as concurrent predictors in regression analysis. Scores on PWI total, the standard of living, personal relationships, community- connectedness, and future security showed no significant negative correlations with motor impulsivity.

As predicted, non-planning impulsivity showed low-to-moderate negative associations with flourishing $(r=-.34, p<.001)$, PWI total $(r=-.19, p<.001)$, achieving in life $(r=-.24, p<.001)$, personal relationships $(r=-.13, p<.01)$, and personal safety domain 
$(r=-.16, p<.001)$. However, relationship between non-planning impulsivity and PWI total score as well as personal safety dropped to nonsignificance in the regression model when all BIS subscales were examined as concurrent predictors in a regression analysis.

Unexpected, non-planning impulsivity showed negatively but onsignificant associations with standard of living $(r=-.06, \beta=.01, p>.01)$, personal health $(r=-.12, B=$ $-.01, p>.01)$, community- connectedness $(r=-.10, \beta=-.11, p>.01)$, and future security domains $(r=-.12, \beta=-.11, p>.01)$.

Table 5: Correlation and regression analyses for BIS 11 Scales predicting scores on SWB Measures

\begin{tabular}{|l|c|c|c|c|c|c|c|}
\hline & \multicolumn{2}{|c|}{$\begin{array}{c}\text { Attention } \\
\text { Impulsivity }\end{array}$} & \multicolumn{2}{c|}{$\begin{array}{c}\text { Motor } \\
\text { Impulsivity }\end{array}$} & \multicolumn{2}{c|}{$\begin{array}{c}\text { Non-Planning } \\
\text { Impulsivity }\end{array}$} & \\
\hline & $r$ & $\beta$ & $r$ & $\beta$ & $r$ & $\beta$ & $R^{2}$ \\
\hline Criterion & & & & & & & \\
\hline Flourishing & $-.33^{* *}$ & $-.25^{* *}$ & $-.17^{* *}$ & .07 & $-.34^{* *}$ & $-.29^{* *}$ & $.17^{* *}$ \\
\hline PWI Total & $-.25^{* *}$ & $-.22^{* *}$ & -.12 & .05 & $-.19^{* *}$ & -.13 & $.09^{* *}$ \\
\hline Standard of Living & $-.18^{* *}$ & $-.21^{* *}$ & -.07 & .04 & -.06 & .01 & $.04^{* *}$ \\
\hline Personal Health & $-.19^{* *}$ & $-.14^{*}$ & $-.15^{*}$ & -.06 & -.12 & -.04 & $.04^{* *}$ \\
\hline Achieving in Life & $-.28^{* *}$ & $-.22^{* *}$ & $-.16^{* *}$ & .03 & $-.24^{* *}$ & $-.18^{* *}$ & $.14^{* *}$ \\
\hline Personal Relationships & $-.14^{*}$ & -.12 & -.03 & .08 & $-.13^{*}$ & $-.14^{*}$ & $.05^{* *}$ \\
\hline Personal Safety & $-.20^{* *}$ & $-.14^{*}$ & $-.16^{* *}$ & -.06 & $-.16^{* *}$ & -.09 & $.06^{* *}$ \\
\hline Community-Connectedness & -.11 & -.13 & -.01 & .12 & -.10 & -.11 & $.04^{*}$ \\
\hline Future Security & $-.14^{*}$ & $-.15^{*}$ & -.02 & .09 & -.12 & -.11 & $.04^{*}$ \\
\hline Note Gender and age & & & & & & & \\
\hline
\end{tabular}

Note: Gender and age included as control. $r=$ Pearson correlations. Standardized regression coefficients $(\beta)$ and $R^{2}$ (squared multiple $R$ ) are from regression models including all three BIS-11 dimensions as predictors of criterion measures.

${ }^{*} p<.01,{ }^{* *} p<.001$

\section{Discussion and conclusions}

The current study aimed to examine the relationship between the different dimensions of impulsivity (i.e. attentional impulsivity, motor impulsivity, and non-planning impulsivity) and indicators of SWB (flourishing and personal wellbeing index) in the student population in private higher education. Furthermore, the current study explored whether these relations differ between men and women. The results partially supported study hypotheses and showed that attention impulsivity and non-planning impulsivity negatively predicted subjective well-being. In terms of regression model betas in the prediction of SWB indicators, the BIS-11 subscales showed distinctive relations and provide further evidence that the three dimensions of impulsivity are distinct, yet partially overlapping components of a complex construct of impulsivity. The results suggested that impulsivity substrates are an important predictor of subjective well-being. Overall, impulsivity substrates together explained from 4 to $17 \%$ of the variance in subjective well-being indexes. Most of the variance was explained in flourishing (17\%) 
and in achieving in life (14\%) which indicates that impulsivity has a strong negative effect on daily functioning and satisfaction with life achievements.

As expected, attention impulsivity predicted low flourishing and low satisfaction with standard of living, personal health, achieving in life, personal safety and future security. However, attention impulsivity was not found to be a negative predictor in explaining satisfaction with personal relationships and satisfaction with communityconnectedness. These findings are consistent with research showing that attention impulsivity associated with indicators of low well-being (Schotanus-Dijkstra et al., 2016) such as high neuroticism (Lange et al., 2017), low academic performance (Lozano et al., 2014), high psychopathy (Malesza \& Ostaszewski, 2016), and low impulse control, organization and strategic planning (Spinella, 2005).

Contrary to expectation, motor impulsivity showed only bivariate but not unique relationships with flourishing and satisfaction with personal health, achieving in life, and personal safety. Unexpectedly, on bivariate level, motor impulsivity was unrelated to the standard of living, personal relationships, and community-connectedness. These results are in line with previous studies showing that motor impulsivity was positively related to some indicators of adaptive functioning such as extraversion (Lange et al., 2017), and narcism (Malesza \& Ostaszewski, 2016). Motor impulsivity includes sensation-seeking which is associated with positive affect and enjoying oneself. It may be that sensation seeking leads to positive emotions, such as hope and excitement, which then turn into well-being.

As predicted, non-planning impulsivity was found to be uniquely associated with lower subjective flourishing, and lower satisfaction with achieving in life and personal relationships. However, contrary to our prediction, non-planning impulsivity was not a negative predictor satisfaction with standard of living, personal health, personal safety, community- connectedness, and future security. Negative urgency and dysregulation of emotions are some of the fundamental features of non-planning impulsivity. Our results are in line with this, suggesting that non-planning impulsivity is related to lower wellbeing mainly through low self-control and negative emotions which are one of the essential components of SWB (Diener et al., 2010; Hofmann et al., 2014).

With respect to the relationship between gender and impulsivity, in this study there were no significant gender differences on the BIS subscales, thus replicating previous studies done on adult members of the community (e.g. Malesza \& Ostaszewski, 2016). Also, gender did not moderate the relationship between BIS subscales and SWB indexes. The present study also demonstrated that the BIS components manifest similarly across gender in relation to indicators of SWB. Results indicated that the relationship between BIS subscales and SWB indexes did not vary across gender, i. e. gender did not moderate the relationship between BIS components and SWB indexes. The results showed that the three components are distinct, yet partially overlapping components of a common construct of impulsivity. BIS subscales differently predicted SWB indexes, thus also suggesting that Barratt's conceptualization of impulsivity has demonstrated discriminative validity. 
In summary, the current study indicated that in both men and women attentional impulsivity is the strongest predictor of low subjective well-being, non-planning impulsivity strongly negatively affects flourishing, and motor impulsivity is not a significant predictor of SWB.

\subsection{Limitation and future directions}

Certain limitations must be borne in mind in interpreting findings from this study. The first limitation of this work is the use of a student sample that may not exhibit the full range of impulsivity. Therefore, future studies should also use general population samples and clinical and incarcerated samples. Second, the use of self-report measures is also a limitation given the impact of shared method variance. Using behavioral tasks of impulsivity would be an advance over the current design (e.g., Malesza, 2016). The study is correlational and, therefore, no causal relationships are confirmed. Notwithstanding these limitations, the current study revealed unique predictive relations for the BIS-11 with the SWB indicators, and, thereby providing new insights into the overlap and distinctiveness among the three impulsivity dimensions.

\section{Funding statement}

This research did not receive any specific grant from funding agencies in the public, commercial, or not-for-profit sectors.

\section{Declaration of conflicting interests}

The author declare no potential conflicts of interest with respect to the research, authorship, and/or publication of this article.

\section{About the Authors}

Dr. Katarina Sokić, Research Associate at Oxford Business College, PhD (Psychology), MSc in Civil Law.

Dr. Fayyaz Hussain Qureshi, Director of Research and Quality Assurance, BA, (Economics and Journalism), BSc (Botany, Zoology and Chemistry), MA (English Literature), MBA (Marketing), MBA (Finance), MSc (Internet Technologies), Doctorate in Marketing, PGD (Organisations Knowledge), Oxford Business College, 65 George Street, Oxford, United Kingdom.

Sarwar Khawaja, Chairman Business Development, MBA, LLM; Chairman Business Development, Oxford Business College, 65 George Street, Oxford, United Kingdom.

\section{References}

American Psychiatric Association (2013). Diagnostic and statistical manual of mental disorders 5th Ed. Washington, DC: American Psychiatric Association (text revision). 
Bakhshani N. (2014). Impulsivity: A Predisposition Toward Risky Behaviors. International Journal of High Risk Behaviors and Addiction, 3(2):e20428. http://dx.doi.org/10.5812/ijhrba.20428.

Barratt, E. S. (1993). Impulsivity: integrating cognitive, behavioral, biological and environmental data. In W. McCowan, J. Johnson, \& M. Shure, The impulsive client: theory, research, and treatment. Washington, DC: American Psychological Association

Blonigen, D. M., Hicks, B., Krueger, R., Patrick, C. J. i Iacono, W. (2005). Psychopathic personality traits: Heritability and genetic overlap with internalizing and externalizing pathology. Psychological Medicine, 35, 637-648. http://dx.doi.org/10.1017/S0033291704004180

Cyders, M. A., Smith, G. T., Spillane, N. S., Fischer, S., Annus, A. M., \& Peterson, C. (2007). Integration of Impulsivity and Positive Mood to Predict Risky Behavior: Development and Validation of a Measure of Positive Urgency. Psychological Assessment, 19(1), 107-118. https://doi.org/10.1037/1040-3590.19.1.107

Coccaro, E. F., Lee, R., \& Kavoussi, R. J. (2010). Aggression, suicidality, and intermittent explosive disorder: Serotonergic correlates in personality disorder and healthy control subjects. Neuropsychopharmacology, 35(2), 435-444.

Coccaro, E. F., Posternak, M. A., \& Zimmerman, M. (2005). Prevalence and features of intermittent explosive disorder in a clinical setting. Journal of Clinical Psychiatry, 66(10), 1221-1227.

Diener, E., Lucas, R. E., \& Oishi, S. (2002). Subjective well-being: The science of happiness and life satisfaction. In C. R. Snyder \& S. J. Lopez (Eds.), The Handbook of Positive Psychology (pp. 213-229). New York: Oxford University Press.

Diener, E., Scollon, C. N., \& Lucas, R. E. (2003). The Evolving Concept of Subjective WellBeing: The Multifaceted Nature of Happiness. Advances in Cell Aging and Gerontology, 15, 187-219. Retrieved from: http://dx.doi.org/10.1007/978-90-481$\underline{2354-4 \quad 4}$

Diener, E., Suh, E. M., Lucas, R. E., \& Smith, H. L. (1999). Subjective well-being: Three decades of progress. Psychological Bulletin, 125(2), 276-302. https://doi.org/10.1037/0033-2909.125.2.276

Diener, E., Wirtz, D., Tov, W., Kim-Prieto, C., Choi, D. won, Oishi, S., \& Biswas-Diener, R. (2010). New well-being measures: Short scales to assess flourishing and positive and negative feelings. Social Indicators Research, 97(2), 143-156. https://doi.org/10.1007/s11205-009-9493-y

Demir, M. (2010). Close relationships and happiness among emerging adults. Journal of Happiness Studies, 11(3), 293-313. https://doi.org/10.1007/s10902-009-9141-x

Dom, G., Hulstijn, W., \& Sabbe, B. (2006). Differences in impulsivity and sensation seeking between early- and late-onset alcoholics. Addictive Behaviors, 31(2), 298308. https://doi.org/10.1016/j.addbeh.2005.05.009

Dougherty, D. M., Mathias, C. W., Marsh, D. M., Papageorgiou, T. D., Swann, A. C., \& Moeller, F. G. (2004). Laboratory Measured Behavioral Impulsivity Relates to 
Suicide Attempt History. Suicide and Life-Threatening Behavior, 34(4), 374-385. https://doi.org/10.1521/suli.34.4.374.53738

Eronen, M., Hakola, P., \& Tiihonen, J. (1996). Mental disorders and homicidal behavior in Finland. Archives of General Psychiatry, 53(6), 497-501.

Fredrickson, B. L. (1998). What good are positive emotions? Review of General Psychology. Review of General Psychology, 2(3), 300-319. https://doi.org/10.1037/1089-2680.2.3.300

Gatner, D. T., Douglas, K. S., \& Hart, S. D. (2016). Examining the Incremental and Interactive Effects of Boldness with Meanness and Disinhibition Within the Triarchic Model of Psychopathy. Personality Disorders: Theory, Research, and Treatment, 7(3), 259-268. https://doi.org/10.1037/per0000182

Goodwin, B. C., Browne, M., Hing, N., \& Russell, A. M. T. (2017). Applying a revised twofactor model of impulsivity to predict health behaviour and well-being. Personality and Individual Differences, 111, 250-255. https://doi.org/10.1016/j.paid.2017.02.029

Goodwin, B. C., Browne, M., Rockloff, M., \& Loxton, N. (2016). Differential Effects of Reward Drive and Rash Impulsivity on the Consumption of a Range of Hedonic Stimuli. Journal of Behavioral Addictions, 5(2), 192-203. https://doi.org/10.1556/2006.5.2016.047

Hecht, L. K., \& Latzman, R. D. (2015). Revealing the nuanced associations between facets of trait impulsivity and reactive and proactive aggression. Personality and Individual Differences, 83, 192-197. doi:10.1016/j.paid.2015.04.021

Hofmann, W., Luhmann, M., Fisher, R. R., Vohs, K. D., \& Baumeister, R. F. (2014). Yes, But Are They Happy? Effects of Trait Self-Control on Affective Well-Being and Life Satisfaction. Journal of Personality, 82(4), 265-277. https://doi.org/10.1111/jopy.12050

Houston, R. J., Stanford, M. S., Villemarette Pittman, N. R., Conklin, S. M., \& Helfritz, L. E. (2003). Neurobiological Correlates and Clinical Implications of Aggressive Subtypes. Journal of Forensic Neuropsychology, 3(4), 67-87. https://doi.org/10.1300/J151v03n04 05

Krueger, R. F., Markon, K. E., Patrick, C. J., Benning, S. D. i Kramer, M. (2007). Linking antisocial behavior, substance use, and personality: An integrative quantitative model of the adult externalizing spectrum. Journal of Abnormal Psychology, 116, 645-666. https://doi.org/10.1037/0021-843X.116.4.645

Lane, S. D., Moeller, F. G., Steinberg, J. L., Buzby, M., Kosten, T. R. (2007). Performance of Cocaine Dependent Individuals and Controls on a Response Inhibition Task with Varying Levels of Difficulty. The American Journal of Drug and Alcohol Abuse, 33(5), 717-726. https://doi.org/10.1080/00952990701522724

Lange, F., Wagner, A., Müller, A., \& Eggert, F. (2017). Subscales of the Barratt Impulsiveness Scale differentially relate to the Big Five factors of personality. Scandinavian Journal of Psychology, 58(3), 254-259. https://doi.org/10.1111/sjop.12359 
Loxton, N. J., \& Dawe, S. (2001). Alcohol abuse and dysfunctional eating in adolescent girls: The influence of individual differences in sensitivity to reward and punishment. International Journal of Eating Disorders, 29(4), 455-462. https://doi.org/10.1002/eat.1042

Lozano, J. H., Gordillo, F., \& Pérez, M. A. (2014). Impulsivity, intelligence, and academic performance: Testing the interaction hypothesis. Personality and Individual Differences, 61-62, 63-68. https://doi.org/10.1016/j.paid.2014.01.013

Malesza, M., \& Ostaszewski, P. (2016). Dark side of impulsivity - Associations between the Dark Triad, self-report and behavioral measures of impulsivity. Personality and Individual Differences, 88, 197-201. https://doi.org/10.1016/j.paid.2015.09.016

Maneiro, L., Gómez-Fraguela, J. A., Cutrín, O., \& Romero, E. (2017). Impulsivity traits as correlates of antisocial behaviour in adolescents. Personality and Individual Differences, 104, 417-422. https://doi.org/10.1016/j.paid.2016.08.045

Moeller, F. G., Barratt, E. S., Dougherty, D. M., Schmitz, J. M., \& Swann, A. C. (2001). Psychiatric aspects of impulsivity. American Journal of Psychiatry, 158, 1783-1793. https://doi.org/10.1176/appi.ajp.158.11.1783

Patrick, C. J., \& Drislane, L. E. (2015). Triarchic Model of Psychopathy: Origins, Operationalizations, and Observed Linkages with Personality and General Psychopathology. Journal of Personality, 83(6), 627-643. https://doi.org/10.1111/jopy.12119

Patrick, C. J. \& Bernat, E. M. (2009). Neurobiology of psychopathy: A two-process theory. U: G. G. Berntson i J. T. Cacioppo (Ur.), Handbook of neuroscience for the behavioral sciences (str. 1110-1131). New York: John Wiley i Sons.

Patrick, C. J., Fowles, D. C., \& Krueger, R. F. (2009). Triarchic conceptualization of psychopathy: Developmental origins of disinhibition, boldness, and meanness. Development and Psychopathology, 21, 913-938. http://dx.doi:10.1017/S0954579409000492

Patton, J. H., Stanford, M. S., \& Barratt, E. S. (1995). Factor structure of the barratt impulsiveness scale. Journal of Clinical Psychology, 51(6), 768-774. https://doi.org/10.1002/1097-4679(199511)51:6\%3C768::aidjclp2270510607\%3E3.0.co;2-1

Paulhus, D. L., \& Williams, K. M. (2002). the Dark Triad: Narcissism, Psychopathy, and Machiavellianism As Predictors of Entrepreneurial Entry (Summary). Journal of Research in Personality, 36, 556-563. https://doi.org/10.1016/S0092-6566(02)00505$\underline{6}$

Pavot, W., \& Diener, E. (2008). The Satisfaction With Life Scale and the emerging construct of life satisfaction. Journal of Positive Psychology, 3(2), 137-152. https://doi.org/10.1080/17439760701756946

Rodriguez-Jimenez, R., Avila, C., Jimenez-Arriero, M. A., Ponce, G., Monasor, R., Jimenez, M., et al. (2006). Impulsivity and sustained attention in pathological gamblers: Influence of childhood ADHD history. Journal of Gambling Studies, 22, 451-461. https://doi.org/10.1007/s10899-006-9028-2 
Qureshi, F. H. \& Khawaja, S. (2021). The Growth of Private Higher Education: An Overview in the Context of Liberalisation, Privatisation and Marketisation. European Journal of Education Studies, 8 (9), 171-186. http://dx.doi.org/10.46827/ejes.v8i9.3896

Qureshi, F. H., Khawaja, S., \& Zia, T. (2020). Mature undergraduate students' satisfaction with online teaching during the COVID-19. European Journal of Education Studies, 7 (12), 456-475. http://dx.doi.org/10.46827/ejes.v7i12.3440

Schotanus-Dijkstra, M., Pieterse, M. E., Drossaert, C. H. C., Westerhof, G. J., de Graaf, R., ten Have, M., ... Bohlmeijer, E. T. (2016). What Factors are Associated with Flourishing? Results from a Large Representative National Sample. Journal of Happiness Studies, 17(4), 1351-1370. https://doi.org/10.1007/s10902-015-9647-3

Skinner, M. D., Aubin, H. J., \& Berlin, I. (2004). Impulsivity in smoking, nonsmoking, and ex-smoking alcoholics. Addictive Behaviors, 29(5), 973-978. https://doi.org/10.1016/j.addbeh.2004.02.045

Smith, P., Waterman, M., \& Ward, N. (2006). Driving aggression in forensic and nonforensic populations: Relationships to self-reported levels of aggression, anger and impulsivity. British Journal of Psychology, 97(3), 387-403. https://doi.org/10.1348/000712605X79111

Sokić, K., Korkut, D., Šestanović, A.(2019). Relationship between Impulsivity, Value Orientations and Impulsive Buying. Managing Global Transitions, 18(3), 195-210. https://doi.org/10.26493/1854-6935.18.195-210

Sokić, K. (2017). Examination of the Triarchic model of psychopathy. Unpublishead doctoral thesis. University of Zagreb, Croatia, Faculty of Humanities and Social Sciences. Retrived from: http://darhiv.ffzg.unizg.hr/id/eprint/9239/

Sophia, B. E. C., Tavares, H., Berti, M. P., Pereira, A. P., Lorena, A., Mello, C., ... Zilberman, M. L. (2009). Pathological Love: and Romantic Relationship. CNS Spectrums, (May), 268-274. https://doi.org/10.1017/S1092852900025438

Sperry, S. H., Lynam, D. R., Walsh, M. A., Horton, L. E., \& Kwapil, T. R. (2016). Examining the multidimensional structure of impulsivity in daily life. Personality and Individual Differences, 94, 153-158. doi:10.1016/j.paid.2016.01.018

Spinella, M. (2005). Self-rated executive function: Development of the executive function index. International Journal of Neuroscience, 115(5), 649-667. https://doi.org/10.1080/00207450590524304

Spinella, M. (2007). Normative data and a short form of the Barratt Impulsiveness Scale. International Journal of Neuroscience, 117(3), 359-368. https://doi.org/10.1080/00207450600588881

Stanford, M. S., Mathias, C. W., Dougherty, D. M., Lake, S. L., Anderson, N. E., \& Patton, J. H. (2009). Fifty years of the Barratt Impulsiveness Scale: An update and review. Personality and Individual Differences, 47(5), 385-395. https://doi.org/10.1016/j.paid.2009.04.008

Swann, A. C., Dougherty, D. M., Pazzaglia, P. J., Pham, M., Steinberg, J. L., \& Moeller, F. G. (2005). Increased impulsivity associated with severity of suicide attempt history 
in patients with bipolar disorder. American Journal of Psychiatry, 162(9), 16801687. https://doi.org/10.1176/appi.ajp.162.9.1680

Swann, A. C., Steinberg, J. L., Lijffijt, M., \& Moeller, F. G. (2008). Impulsivity: Differential relationship to depression and mania in bipolar disorder. Journal of Affective Disorders, 106(3), 241-248. https://doi.org/10.1016/j.jad.2007.07.011

Tan, K., Jarnecke, A. M., \& South, S. C. (2017). Impulsivity, communication, and marital satisfaction in newlywed couples. Personal Relationships, 24(2), 423-439. https://doi.org/10.1111/pere.12190

Van Den Eynde, F., Senturk, V., Naudts, K., Vogels, C., Bernagie, K., Thas, O., ... Audenaert, K. (2008). Efficacy of quetiapine for impulsivity and affective symptoms in borderline personality disorder. Journal of Clinical $\begin{array}{ll}\text { Psychopharmacology, 28(2), 147-155. } & \text { 28 }\end{array}$ https://doi.org/10.1097/JCP.0b013e318166c4bf

Vigil-Coleț, A., \& Morales-Vives, F. (2005). How Impulsivity is Related to Intelligence and Academic Achievement. The Spanish Journal of Psychology, 8(2), 199-204. https://doi.org/10.1017/S1138741600005072

Whiteside, S. P., \& Lynam, D. R. (2001). The Five Factor Model and impulsivity : Using a structural model of personality to understand impulsivity The Five Factor Model and impulsivity: using a structural model of personality to understand impulsivity, Personality and Individual Differences, 30(4), 669-689. https://doi.org/10.1016/S0191-8869(00)00064-7

Xia, L., Gu, R., Zhang, D., \& Luo, Y. (2017). Anxious Individuals Are Impulsive DecisionMakers in the Delay Discounting Task: An ERP Study. Frontiers in Behavioral Neuroscience, 11(January), 1-11. https://doi.org/10.3389/fnbeh.2017.00005

Young, S. E., Stallings, M. C., Corley, R. P., Krauter, K. S. i Hewitt, J. K. (2000). Genetic and environmental influences on behavioral disinhibition. American Journal of Medical Genetics (Neuropsychiatric Genetics), 96(5), 684-695. 
Katarina Sokić, Fayyaz Hussain Qureshi, Sarwar Khawaja

THE ROLE OF IMPULSIVITY IN PREDICTING THE SUBJECTIVE

WELL-BEING OF STUDENTS IN PRIVATE HIGHER EDUCATION

Creative Commons licensing terms

Author(s) will retain the copyright of their published articles agreeing that a Creative Commons Attribution 4.0 International License (CC BY 4.0) terms will be applied to their work. Under the terms of this license, no permission is required from the author(s) or publisher for members of the community to copy, distribute, transmit or adapt the article content, providing a proper, prominent and unambiguous attribution to the authors in a manner that makes clear that the materials are being reused under permission of a Creative Commons License. Views, opinions and conclusions expressed in this research article are views, opinions and conclusions of the author(s). Open Access Publishing Group and European Journal of Education Studies shall not be responsible or answerable for any loss, damage or liability caused in relation to/arising out of conflicts of interest, copyright violations and inappropriate or inaccurate use of any kind content related or integrated into the research work. All the published works are meeting the Open Access Publishing requirements and can be freely accessed, shared, modified, distributed and used in educational, commercial and non-commercial purposes under a Creative Commons Attribution 4.0 International License (CC BY 4.0). 